\title{
MAPK inhibitors and pifithrin-alpha block cinnamaldehyde-induced apoptosis in human PLC/PRF/5 cells
}

\author{
Shu-Jing $\mathrm{Wu}^{\text {a }}$, Lean-Teik $\mathrm{Ng}$ b,* \\ a Department of Nutritional Health, Chia-Nan University of Pharmacy and Science, Tainan, Taiwan \\ b Department of Biotechnology, Tajen University, Pingtung, Taiwan
}

Received 13 April 2006; accepted 23 May 2007

\begin{abstract}
Cinnamaldehyde (Cin) has been shown to be effective in inducing apoptotic cell death in a number of human cancer cells. The aim of this study was to investigate the effect of pifithrin-alpha (PFT $\alpha$; a specific p53 inhibitor) and mitogen-activated protein kinases (MAPKs) inhibitors [namely SP600125 (a specific JNK inhibitor), SB203580 (a specific p38 inhibitor) and PD98059 (a specific ERK inhibitor)] on apoptotic signaling transduction mechanism induced by Cin in human hepatoma PLC/PRF/5 (CD95-negative) cells. Using XTT assay, Cin exhibited a powerful cytotoxic effect and apoptotic induction in PLC/PRF/5 cells. Apoptosis was elicited when cells were treated with $1 \mu \mathrm{M}$ Cin as characterized by morphological changes and the appearance of phosphatidylserine on the outer surface of the plasma membrane. Cin down-regulated the expression of Bcl-xL, up-regulated mutant $\mathrm{p} 53$ and Bax proteins and promoted caspase-3 to active forms, as well as cleaving poly (ADP-ribose) polymerase (PARP) in a time-dependent pattern. This could be supported by the activation and phosphorylation of MAPKs, including JNK, ERK and p38 kinases. Pre-incubation with PFT $\alpha$ and specific MAPK inhibitors significantly diminished the effect of Cin-induced apoptosis. The activities of anti-apoptotic (Bcl- $\left.{ }_{\mathrm{XL}}\right)$ and pro-apoptotic (Bax) proteins were remarkably affected by PFT $\alpha$ and PD98059 pre-treatment. PFT $\alpha$ effectively blocked PARP cleavage in cells treated with Cin, and also markedly prevented the phosphorylation of JNK, p38 and ERK proteins. These results suggest that p53 induction and MAPK signaling pathways are required for Cin-mediated apoptosis in PLC/PRF/5 cells.
\end{abstract}

(C) 2007 Elsevier Ltd. All rights reserved.

Keywords: Cinnamaldehyde; PFT $\alpha$; MAPK inhibitors; Apoptosis; PLC/PRF/5 cells

\section{Introduction}

Programmed cell death, or apoptosis, is central to the process of animal development and tissue homeostasis (Meier et al., 2000). It is now believed that failure to regulate apoptosis is linked to a number of human pathologies such as cancer, autoimmune diseases and neuro-degenerative disorders (Thompson, 1995; Kroemer and Reed, 2000).

Cinnamaldehyde (Cin) is a bioactive compound isolated from the stem bark of Cinnamomum cassia Presl. (Lauraceae), which has been widely used in folk medicine as anticancer (Ka et al., 2003), antibacterial (Chang et al., 2001),

\footnotetext{
* Corresponding author. Tel.: +886 8 7624002x450; fax: +8868 7621645 .

E-mail address: 1thuang@mail.tajen.edu.tw (L.-T. Ng).
}

antimutagenic (Shaughnessy et al., 2001), immunomodulatory (Koh et al., 1998), and as remedies for treating other diseases (Perry, 1980). Studies have demonstrated that Cin-induced the generation of ROS, reduction of mitochondrial membrane potential, release of cytochrome $c$ and activation of caspase activity in human leukemia HL-60 cells (Usta et al., 2002; Ka et al., 2003).

p53 directly activated the promoter of the CD95 (APO-1) gene in response to DNA damage by anticancer agents, and the up-regulation of the CD95 death receptor, which was observed only in cells with wild-type p53 but not in cells with mutant or null p53 (Muller et al., 1998). Activation of the tumor suppressor protein p53 results in altered transcription of a wide variety of genes involving in cell metabolism, cell cycle regulation and apoptosis (Lee et al., 2003). Both pro-apoptotic (Bax, Bak, Bid, Noxa, etc) and 
anti-apoptotic (Bcl-2, Bcl-xL, Mcl-1, Bcl-w, etc) are known to be key regulators of apoptosis (Adams and Cory, 1998). Genes transcriptionally up-regulated by $\mathrm{p} 53$ that have been implicated in promoting apoptosis include the Bcl-2 family members, namely Bax, Bak and Noxa gene proteins (Karpinich et al., 2002; Borner, 2003; Lee et al., 2003). The activation of caspase- 3 is required for p53-dependent apoptotic pathway, which leads to the cellular protein cleavage (e.g., PARP), DNA damage and cell death.

The Jun-N-terminal kinase (JNK), p38 MAP kinase (p38) and extracellular signal-regulated kinase (ERK) are belong to the superfamily of mitogen-activated protein kinases (MAPKs). MAPKs, a family of serine/threonine protein kinases, are capable of phosphorylating numerous cytoplasmic and nuclear targets (Chang and Karin, 2001). In general, the JNK and p38 are activated by proinflammatory cytokines and environmental stresses such as UV irradiation, heat, hydrogen peroxide and DNA damage, whereas ERK plays a major role in regulating cell growth and differentiation (Xia et al., 1995; Ichijo, 1999). Importantly, pharmacological or molecular modulation of MAPK signaling has been shown in many cases to influence the apoptotic response to antitumor agents (Dent and Grant, 2001; Fan and Chambers, 2001). In our preliminary study, Cin exhibited strong growth inhibition in hepatoma (PLC/PRF/5) cells and its mode of action was through the activation and phosphorylation of MAPK pathway ( $\mathrm{Wu}$ et al., 2005). Both SP600125 (a specific JNK inhibitor) and SB203580 (a specific p38 inhibitor) significantly prevented the phosphorylation of JNK and p38 proteins. In addition, MAPK inhibitors markedly blocked druginduced cell death and the apoptotic mechanism(s) (Zhang et al., 2004).

Pifithrin-alpha (PFT $\alpha)$ is a chemical compound able to suppress p53-mediated transactivation (Komarov et al., 1999). It significantly decreased p53 expression on wild type p53 cells, but had no effect on mutant p53 cells or p53 deficient cells (Charlot et al., 2006). Moreover, it would be interesting to find out if PFT $\alpha$ could affect other signal transduction pathways besides p53.

In the present study, our aims were (i) to evaluate the antihepatoma activity of Cin in human hepatoma PLC/ $\mathrm{PRF} / 5$ (CD95-negative) cells; (ii) to investigate the role of $\mathrm{p} 53$, and activation and phosphorylation of MAPKs (JNK, p38 and ERK) in Cin-mediated apoptosis; (iii) to examine the effects of PFT $\alpha$ (a p53 inhibitor) and MAPK inhibitors including JNK (SP600125), p38 (SB203580) and ERK (PD98059) on p53, Bcl-2 family proteins, PARP cleavage and caspase-3 activation; and (iv) to study the affects of PFT $\alpha$ on the MAPK pathways.

\section{Materials and methods}

\subsection{Reagents}

Dulbecco's modified Eagle's medium (DMEM), dimethyl sulfoxide (DMSO), sodium 3'-[1-(phenyl-amino-carbonyl)-3,4-tetrazolium]-bis (4methoxy-6-nitro) benzene sulfonic acid (XTT), 3-(4,5-dimethylthiazol-2- yl)-2,5-diphenyl-tertazolium bromide (MTT), penicillin, streptomycin, trypsin-EDTA, and anti- $\beta$-actin were purchased from Sigma Chemical Co. (St. Louis, MO, USA). Fetal bovine serum (FBS) was obtained from GIBCO BRL (Gaithersburg, MD, USA). Pifithrin-alpha (PFT $\alpha$ ), and JNK (SP600125), p38 (SB203580) and ERK (PD98059) inhibitors were purchased from Calibiochem (San Diego, CA, USA). The anti-Bax, anti-Bcl-xL, anti-caspase-3, anti-CD95 (APO-1/CD95), anti-p53, antiPARP, anti-JNK/SAPK1, anti-phospho-JNK (pT183/pY185), anti-p38a/ SAPK2a, anti-phospho-p38 (pT180/pY182), anti-ERK, anti-phosphoERK (pT202/pY204) and anti-rabbit IgG antibodies were purchased from PharMingen (San Diego, CA, USA). Anti-mouse IgG antibody was from Promega (Madison, WI, USA).

\subsection{Cell cultures and drug preparation}

The PLC/PRF/5 (ATCC CRL 8024; hepatitis B surface antigen, HBsAg [+]) was obtained from the American Type Culture Collection (Rockville, MD, USA). It is a poorly differentiated cell line deriving from a patient with HBV (Koch et al., 1984). Cells were grown in 90\% DMEM supplemented with $10 \% \mathrm{FBS}, 100 \mathrm{units} / \mathrm{ml}$ penicillin and $100 \mu \mathrm{g} / \mathrm{ml}$ streptomycin. They were maintained at $37{ }^{\circ} \mathrm{C}$ in a humidified atmosphere of $5 \% \mathrm{CO}_{2}$.

The Cin stock solution was prepared in DMSO at concentration $10 \mathrm{mM}$ and was stored at $-20^{\circ} \mathrm{C}$ until use. The concentrations used for the study were $0.1,0.5,1$ and $5 \mu \mathrm{M}$, which were freshly prepared for each experiment with a final DMSO concentration of $0.1 \%$. Controls were always treated with the same amount of DMSO $(0.1 \% \mathrm{v} / \mathrm{v})$ as used in the corresponding experiments.

\subsection{Antihepatoma activity assay}

The percentage of apoptotic cells was measured by XTT colorimetric assay according to the manufacturer's instructions. In brief, cells were seeded at a density of $1 \times 10^{5}$ cells/well onto 96 -well culture plates, and then left to adhere to the plastic plates overnight before being exposed to $0.1 \%$ DMSO and various concentrations of Cin $(0.1,0.5,1$ and $5 \mu \mathrm{M})$. After 0 , 6,12 and $24 \mathrm{~h}$ of treatment, $100 \mu \mathrm{l}$ of XTT solution were added to each well and then incubated for $4 \mathrm{~h}$. The absorbance was measured with an ELISA reader (Multiskan EX, Labsystems, Helsinki, Finland) at a test wavelength of $492 \mathrm{~nm}$ and a reference wavelength of $690 \mathrm{~nm}$.

\subsection{Detection of Cin-induced apoptosis}

The Annexin V-FITC Apoptosis Detection kit (Roche Diagnostics $\mathrm{GmbH}$, Germany) was used to label the externalized phosphatidylserine according to the manufacturer's protocol. The analysis was performed with a flow cytometer (Coulter Epics Elite ESP; Miami, FL, USA) equipped with a $488 \mathrm{~nm}$ argon laser. Approximately 10,000 cells were evaluated for each sample. Gating of control nonapoptotic populations (cells treated with $0.1 \%$ DMSO) was used as a reference to compare with treatments with Cin.

\subsection{Detection of apoptotic cell morphology}

Cells were untreated (control) or treated with 0.5 and $1 \mu \mathrm{M}$ Cin for $24 \mathrm{~h}$. They were fixed with $3.7 \%$ paraformaldehyde at room temperature for $20 \mathrm{~min}$. After washing with PBS, cells were stained with $1.6 \mu \mathrm{M}$ Hoechst 33258 in the dark for $20 \mathrm{~min}$. Morphological changes were observed under fluorescent microscopy (Zeiss Axioskop, Mikron Instruments, NY, USA).

\subsection{Cytotoxity assay}

In brief, cells were seeded at a density of $1 \times 10^{5}$ cells/well onto 12-well plates with $0.1 \%$ DMSO (control) or $1 \mu \mathrm{M}$ Cin only or cells were pretreated with $30 \mu \mathrm{M}$ PFT $\alpha$ or with each of the MAPK inhibitors $(20 \mu \mathrm{M}$ 
JNK or $25 \mu \mathrm{M}$ p38 or $50 \mu \mathrm{M}$ ERK) for $1 \mathrm{~h}$ before adding Cin. Cells were washed once before adding $50 \mu \mathrm{l}$ of FBS-free medium containing MTT $(5 \mathrm{mg} / \mathrm{ml})$. After $4 \mathrm{~h}$ of incubation at $37^{\circ} \mathrm{C}$, the medium was discarded and the formazan blue that formed in the cells was dissolved in DMSO. The optical density was measured at $550 \mathrm{~nm}$. The percentage of cell growth inhibition was calculated as follows:

Cell death $(\%)=\left[A_{550}(\right.$ control $)-A_{550}($ Cin $\left.)\right] / A_{550}($ control $) \times 100$

\subsection{Western immunoblot analysis}

Cells were harvested and lysed in ice-cold buffer $(10 \mathrm{mM}$ Tris- $\mathrm{HCl}, \mathrm{pH}$ $7.5,0.1 \%$ NP- $40,0.5 \%$ sodium deoxycholate, $0.1 \%$ SDS, $1 \mathrm{mM}$ sodium orthovanate and $120 \mathrm{mM}$ sodium chloride) containing $1 \mathrm{mM}$ phenylmethylsulfonyl fluoride, $10 \mu \mathrm{g} / \mathrm{ml}$ leupeptin and $1 \mu \mathrm{g} / \mathrm{ml}$ aprotonin (Sigma Chemical Co., St. Louis, MO, USA). Lysates were centrifuged at $10,000 \mathrm{~g}$ for $10 \mathrm{~min}$. Equal amounts of lysate protein $(50 \mu \mathrm{g} / \mathrm{lane})$ were loaded onto SDS-polyacrylamide gels and electrophoretically transferred to a PVDF membrane (Bio-Rad Laboratories, Hercules, CA, USA). After inhibiting the nonspecific binding sites with $5 \%(\mathrm{w} / \mathrm{v})$ skim milk in $0.1 \%(\mathrm{v} / \mathrm{v})$ Tween 20 containing PBS (PBST) for $1 \mathrm{~h}$ at room temperature. The membrane was incubated with the specific primary antibodies [i.e., anti-Bax (1:250), anti-Bcl-xL (1:500), anti-caspase-3 (1:1000), anti-CD95 (APO-1/CD95) (1:5000) and anti-p53 (1:500)], MAPK primary antibodies [i.e., anti-JNK/ SAPK1 (1:250), anti-phospho-JNK (pT183/pY185) (1:250), anti-p38a/ SAPK2a (1:5000), anti-phospho-p38 (pT180/pY182) (1:2500), anti-ERK (1:5000), anti-phospho-ERK (pT202/pY204) (1:1000)], and anti-B-actin $(1: 5000)$ antibodies in $5 \%(\mathrm{w} / \mathrm{v})$ skim milk in PBST for $1 \mathrm{~h}$ at room temperature. Antibody recognition was detected with the respective secondary antibody, either anti-mouse $\mathrm{IgG}$ or anti-rabbit IgG antibody linked to the horseradish peroxidase. Antibody-bound proteins were detected by the ECL western blotting analysis system (Amersham, Aylesbury, UK). The expression of $\beta$-actin was used as a control.

\subsection{Statistical analysis}

Data were presented as means \pm standard deviations (SD) from three independent experiments. Values were evaluated by one way ANOVA, followed by Duncan's multiple range tests. Differences were considered significant when $P$-value was $<0.05$.

\section{Results}

\subsection{Antihepatoma activity}

To examine the effects of Cin on human hepatoma PLC/ $\mathrm{PRF} / 5$ cell death, cells were treated with $0-5 \mu \mathrm{M}$ Cin for $0,6,12$, and $24 \mathrm{~h}$. After Cin-treatment, the percentage decrease in viable cell number was evaluated by XTT assay. Results showed that cells treated with $1 \mu \mathrm{M}$ Cin for 12 and
$24 \mathrm{~h}$ exhibited $47.00 \pm 1.50 \%$ and $64.30 \pm 0.96 \%$ cell death in the culture, respectively (Table 1). However, a significantly higher number of cell death was noted at concentration $5 \mu \mathrm{M}$ Cin for $24 \mathrm{~h}(92.30 \pm 0.40 \%)$. The result also indicated that Cin-induced cytotoxicity on PLC/PRF/5 cells in dose- and time-dependent manners.

\subsection{Induction of apoptosis by Cin}

To examine the effect of Cin treatment on cell morphology during cell death, morphological changes in untreated cells (Control; $0.1 \%$ DMSO) and cells treated with 0.5 and $1 \mu \mathrm{M}$ Cin for $24 \mathrm{~h}$ were examined by staining with Hoechst 33,258 , and then analyzed by fluorescent microscopy. The results demonstrated that the nuclear fragmentation and chromatin compaction were noted on Cin-induced cell apoptosis (Fig. 1a). This further supports that Cin-induced apoptosis in PLC/PRF/5 cells.

To further confirm the finding that Cin-induced apoptosis, PLC/PRF/5 cells were stained with Annexin V-FITC and propidium iodide, and subsequently analyzed by flow cytometry. The Annexin V assay measures phospholipids turnover from the inner to the outer lipid layer of the plasma membrane, an event typically associated with apoptosis. As indicated by FACS analysis, the proportion of Annexin V-staining cells was found to increase in $1 \mu \mathrm{M}$ Cin-treated cells. After $24 \mathrm{~h}$ of treatment, the percentage of Annexin V-staining cells was $0.13 \%$ for control $(0.1 \%$ DMSO), $49.36 \%$ for $0.5 \mu \mathrm{M}$ Cin and $68.05 \%$ for $1 \mu \mathrm{M}$ Cin (Fig. 1b). PLC/PRF/5 cells treated with Cin exhibited a significant increase in the number of apoptotic cells in a dose-dependent fashion.

\subsection{Cin treatment down-regulates protein level of $B c l_{-X L}$, up-regulates protein levels of Bax and $p 53$ in PLC/PRF/5 cells}

We evaluated the expression levels of $\mathrm{p} 53$ and Bcl-2 family proteins in PLC/PRF/5 cells which were treated with $1 \mu \mathrm{M}$ Cin for $0,6,12$ and $24 \mathrm{~h}$. As shown in Fig. 2a, treatment with $1 \mu \mathrm{M}$ Cin results in the down-regulation of the anti-apoptotic $\left(\mathrm{Bcl}^{-\mathrm{xL}}\right)$ protein and the up-regulation of the pro-apoptotic (Bax) protein in a time-dependent fashion. The expression of $\mathrm{Bcl}_{-\mathrm{XL}}$ protein was gradually

Table 1

Cin-induced cytotoxicity on human PLC/PRF/5 cells

\begin{tabular}{|c|c|c|c|c|}
\hline \multirow[t]{2}{*}{ Treatment $(\mu \mathrm{M})$} & \multicolumn{4}{|c|}{$\%$ Decrease in viable cell number } \\
\hline & $0 \mathrm{~h}$ & $6 \mathrm{~h}$ & $12 \mathrm{~h}$ & $24 \mathrm{~h}$ \\
\hline 0 & $0.00 \pm 0.00^{\mathrm{b}}$ & $0.00 \pm 0.00^{\mathrm{c}}$ & $0.00 \pm 0.00^{\mathrm{d}}$ & $0.00 \pm 0.00^{\mathrm{e}}$ \\
\hline 0.5 & $0.00 \pm 0.00^{\mathrm{b}}$ & $0.80 \pm 0.07^{\mathrm{c}}$ & $12.10 \pm 1.20^{\mathrm{c}}$ & $47.80 \pm 1.63^{\mathrm{c}}$ \\
\hline 1 & $0.50 \pm 0.03^{\mathrm{b}}$ & $11.40 \pm 0.90^{\mathrm{b}}$ & $47.00 \pm 1.50^{\mathrm{b}}$ & $64.30 \pm 0.96^{\mathrm{b}}$ \\
\hline 5 & $6.80 \pm 0.02^{\mathrm{a}}$ & $31.00 \pm 1.25^{\mathrm{a}}$ & $78.70 \pm 0.65^{\mathrm{a}}$ & $92.30 \pm 0.40^{\mathrm{a}}$ \\
\hline
\end{tabular}

Data are presented as means \pm SD of three independent experiments. Values within the same column with the different superscript letters were significantly different at $P<0.05$ based on Duncan's multiple range tests. 
a

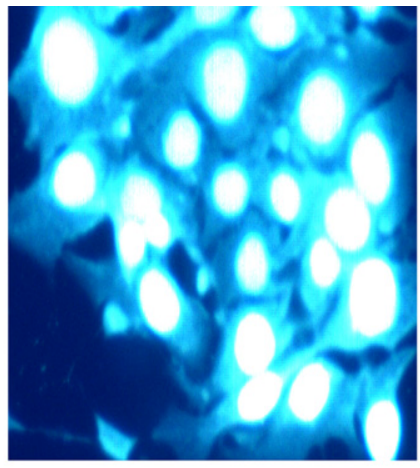

Control

b

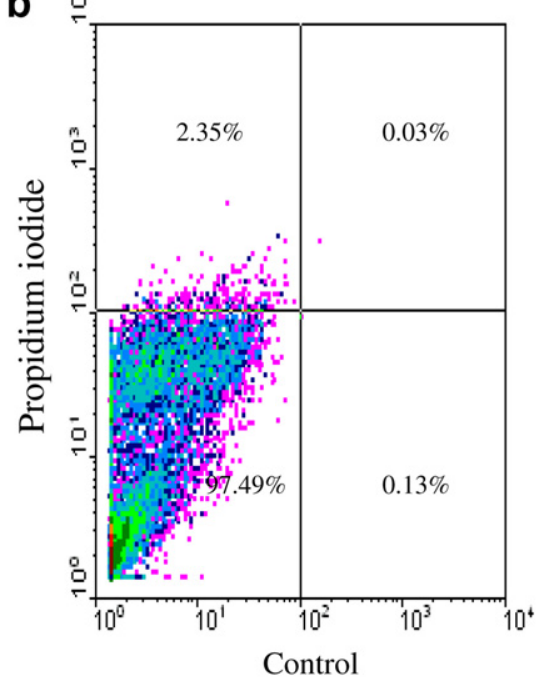

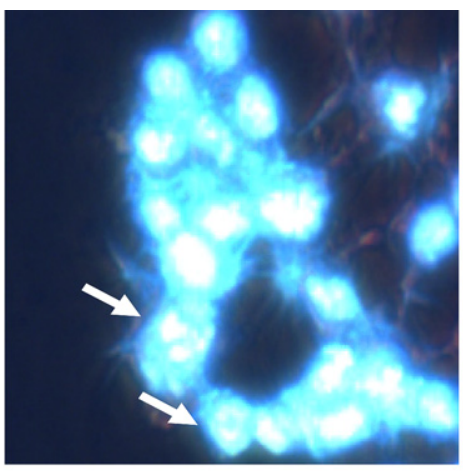

$0.5 \mu \mathrm{M} \mathrm{Cin}$

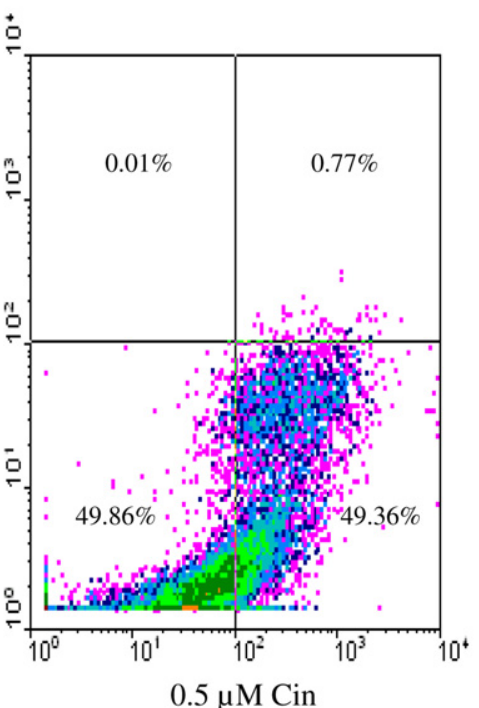

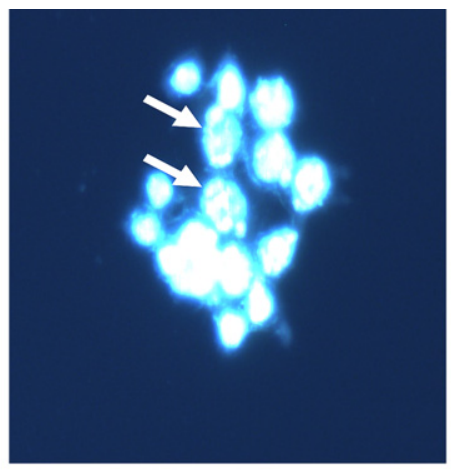

$1 \mu \mathrm{M}$ Cin

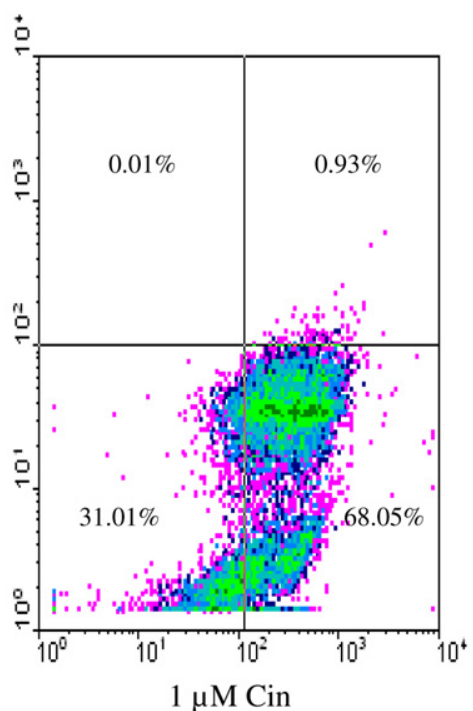

Annexin-V Binding

Fig. 1. Induction of apoptosis by Cin in PLC/PRF/5 cells. (a) Morphological changes in cells of untreated (Control; $0.1 \%$ DMSO) or treated with $0.5 \mu \mathrm{M}$ and $1 \mu \mathrm{M}$ Cin for $24 \mathrm{~h}$ were examined by staining with Hoechst 33258. The arrow point shows the condensation and fragmentation of nuclei in the Cintreated apoptotic cells. (b) Flow cytometric analysis of Annexin V-FITC and propidium iodide double stained cells. Cells were untreated (Control; 0.1\% DMSO) or treated with $0.5 \mu \mathrm{M}$ and $1 \mu \mathrm{M}$ Cin for $24 \mathrm{~h}$. Data were obtained from three independent experiments.

disappeared after 12 and $24 \mathrm{~h}$ of Cin treatment. As expected, Cin did cause an increase in the level of p53 as PLC/PRF/5 cells contain mutant p53 (Mitry et al., 2000). These results indicate that the expression levels of mutant p53 and Bcl-2 family members modulate Cin-induced cell apoptosis in a time-dependent manner.

\subsection{Cin-induced apoptosis exhibits caspase-3 activation and PARP cleavage}

To further confirm the Cin-induced apoptosis, PLC/ $\mathrm{PRF} / 5$ cells were treated with Cin for $0,6,12$ and $24 \mathrm{~h}$, followed by immunoblotting analysis of caspase- 3 activity and PARP cleavage. As shown in Fig. 2b, the activation of caspase-3 after $6 \mathrm{~h}$ of incubation with $1 \mu \mathrm{M}$ Cin was corroborated by the appearance of a $20 \mathrm{kDa}$ fragment of caspase-3, which was resulted from the proteolytic processing of procaspase-3 (32 kDa). PARP proform (molecular mass,
$116 \mathrm{kDa}$ ) was cleaved to give a $\sim 85 \mathrm{kDa}$ fragment in Cintreated cells at 12 and $24 \mathrm{~h}$ after treatment. Among the various substrates that are broken down during apoptosis, PARP is recognized as a useful indicator of apoptosis (Wolf and Green, 1999).

\subsection{Effects of PFT $\alpha$ and MAPK specific inhibitors on Cin-induced apoptosis}

To determine whether the Cin induction of apoptosis were affected by the presence of PFT $\alpha$ (the p53 inhibitor), or JNK inhibitor (SP600125), p38 inhibitor (SB203580) and ERK inhibitor (PD98059) on PLC/PRF/5 cells, cells were pre-incubated with these inhibitors for $1 \mathrm{~h}$, and then induced to undergo apoptosis by treatment with Cin. As shown in Fig. 3a, PFT $\alpha$ significantly inhibited Cin-induced cell death. Pre-treatment with JNK, p38 and ERK inhibi- 

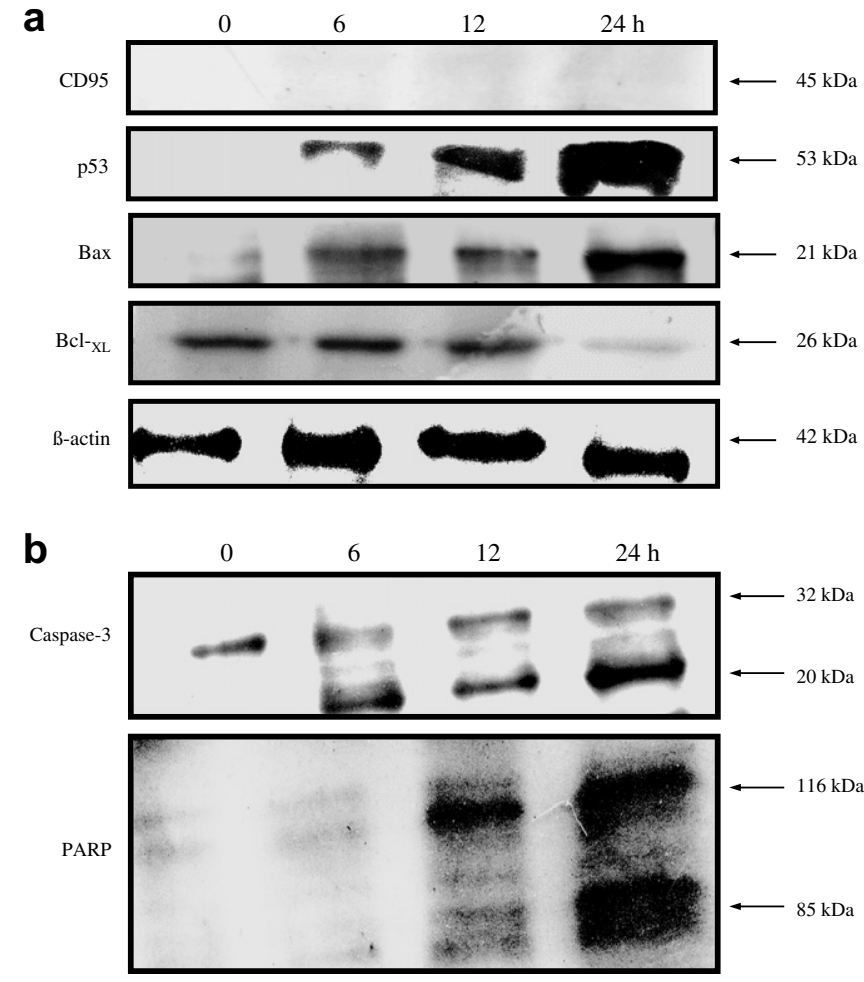

Fig. 2. Involvement of apoptotic signal transduction factors (CD95, Bcl-2 family proteins, p53, caspase-3 and PARP) in Cin-induced cell death. (a) Effect of $1 \mu \mathrm{M}$ Cin on expression of CD95, p53, Bax and $\mathrm{Bcl}_{-\mathrm{xL}}$ proteins at $0,6,12$ and $24 \mathrm{~h}$ in PLC/PRF/5 cells. (b) Effect of $1 \mu \mathrm{M}$ Cin on the expression of PARP cleavage and activation of caspase-3 at $0,6,12$ and $24 \mathrm{~h}$ in PLC/PRF/ 5 cells. $\beta$-actin was used as a positive control.

tors also significantly blocked the number of death cells by Cin (Fig. 3b).

\subsection{Effects of PFT $\alpha$ and MAPK specific inhibitors on Cin-induced apoptotic pathway}

To evaluate the relative role of $\mathrm{p} 53$, Bcl-2 family proteins (Bax, Bcl- ${ }_{\mathrm{XL}}$ ), and PARP cleavage in the Cin-induced apoptotic events, $\mathrm{PLC} / \mathrm{PRF} / 5$ cells were pretreated with a p53 inhibitor $(\mathrm{PFT} \alpha)$ or the specific MAPK inhibitors including JNK (SP600125), p38 (SB203580) and ERK (PD98059) inhibitors. Results displayed that pre-incubation of $\mathrm{PLC} / \mathrm{PRF} / 5$ cells with $30 \mu \mathrm{M}$ PFT $\alpha$ efficiently inhibited the expression of Bax, and the cleavage of PARP at $24 \mathrm{~h}$ after Cin treatment, but had no effect on mutant p53 PLC/PRF/5 cells (Fig. 4). Moreover, pretreatment of cells with $30 \mu \mathrm{M}$ PFT $\alpha$ only or $30 \mu \mathrm{M}$ PFT $\alpha+1 \mu \mathrm{M}$ Cin also prevented the down-regulation of $\mathrm{Bcl}_{-\mathrm{XL}}$. The role of MAPK inhibitors (SP600125, SB203580 and PD98059) was conducted to determine the influence of $\mathrm{p} 53$-dependent pathway on Cin-induced apoptosis. PLC/PRF/5 cells treated with $20 \mu \mathrm{M}$ SP600125 only resulted in the disappearance of mutant p53, Bax and PARP. Pre-treatment of cells with $20 \mu \mathrm{M}$ SP 600125 for $1 \mathrm{~h}$, followed by adding $1 \mu \mathrm{M}$ Cin resulted in an inhibition of Cin-induced Bax and $\mathrm{Bcl}_{\mathrm{XL}}$ expression. Co-treatment of p38 inhibitor
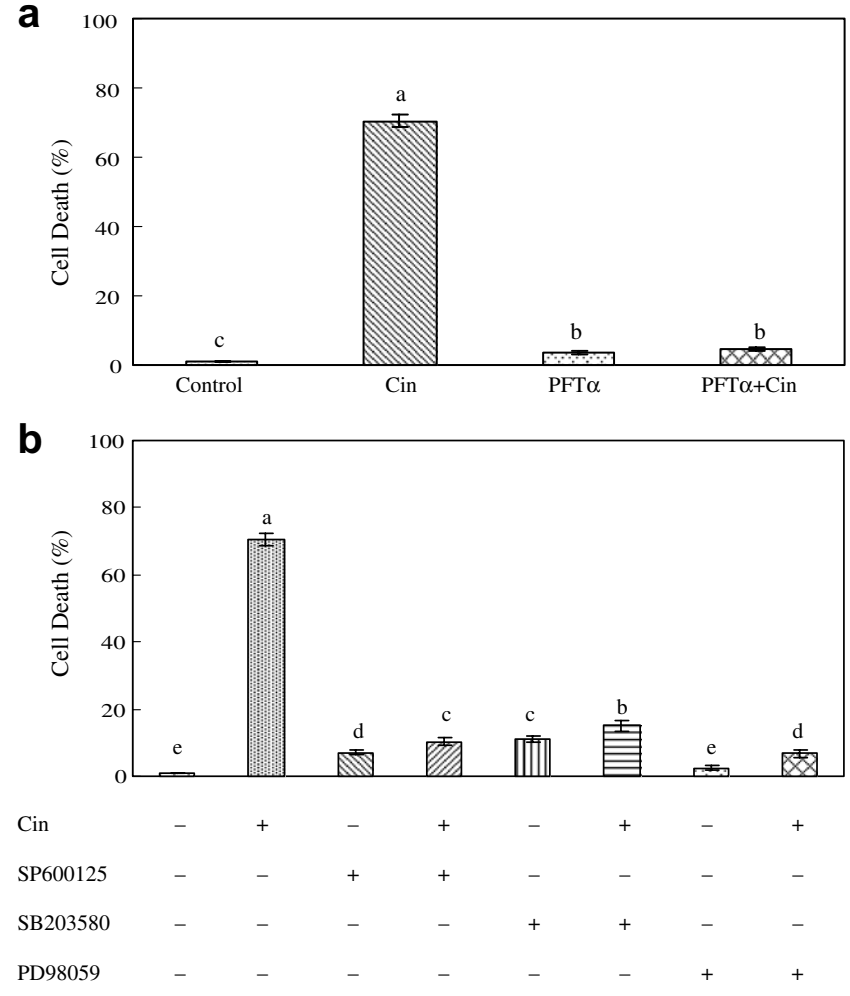

Fig. 3. Effect of the p53 (PFT $\alpha$ ), JNK, p38 and ERK inhibitors on Cininduced apoptosis. PLC/PRF/5 cells were treated without or with $30 \mu \mathrm{M}$ PFT $\alpha, 20 \mu \mathrm{M}$ JNK inhibitor (SP600125), $25 \mu \mathrm{M}$ p38 inhibitor (SB203580) and $50 \mu \mathrm{M}$ ERK inhibitor (PD98059) for $1 \mathrm{~h}$, and then in the presence or absence of $1 \mu \mathrm{M}$ Cin for $24 \mathrm{~h}$. After incubation, the death cell number was determined by MTT assay. (a) Effect of the PFT $\alpha$; (b) Effects of JNK, p38 and ERK inhibitors. Data are presented as means \pm SD of three independent experiments. Values with the different superscript letters were significantly different at $P<0.05$ as analyzed by Duncan's multiple range tests.

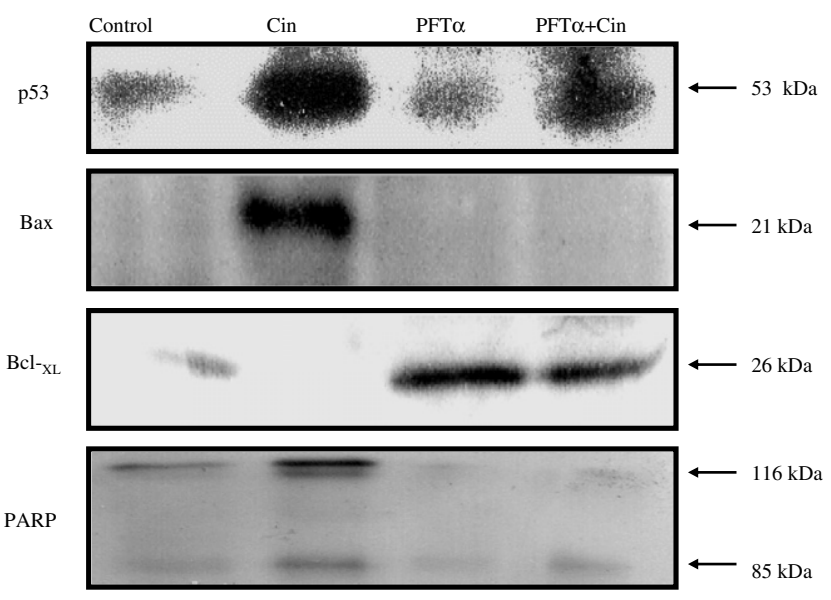

Fig. 4. PFT $\alpha$ prevented Cin-induced cell death and altered the expression pattern of apoptosis related proteins. PLC/PRF/5 cells were untreated (Control; $0.1 \%$ DMSO) or treated with Cin alone or pretreated with $30 \mu \mathrm{M}$ PFT $\alpha$ for $1 \mathrm{~h}$ and then incubated with $1 \mu \mathrm{M}$ Cin for $24 \mathrm{~h}$. Cells were harvested and analyzed by the Western blotting. PFT $\alpha$ inhibited the down-regulation of Bcl-xL, up-regulation of Bax and cleavage of PARP in Cin-treated cells. 
(SB203580) with Cin led to an increase in mutant p53 and Bax expression levels, and PARP cleavage. Cells treated with $50 \mu \mathrm{M}$ PD98059 only resulted in the disappearance of Bax and PARP cleavage. Co-treatment of cells with $50 \mu \mathrm{M}$ PD98059 and $1 \mu \mathrm{M}$ Cin led to the vanishment of Bax protein, but not the $\mathrm{Bcl}_{-\mathrm{XL}}$ and mutant p53 (Fig. 5).

\subsection{Activation and phosphorylation of MAPKs by Cin}

In the investigation of the role of MAPK signal transduction pathway in Cin-induced apoptosis, we found that exposure of PLC/PRF/5 cells to Cin resulted in a dosedependent phosphorylation and activation of all three major MAPKs, namely JNK, ERK and p38 (Fig. 6a). An increase in the activation of JNK, p38 and ERK was noted when the Cin concentration reached $1 \mu \mathrm{M}$. This result suggests that the death of $\mathrm{PLC} / \mathrm{PRF} / 5$ cells induced by Cin is mediated through the MAPK pathways during apoptosis.

\subsection{PFTa alters MAPKs phosphorylation}

In this experiment, we determined whether the expression levels of MAPK family proteins were affected by the presence of PFT $\alpha$ in Cin-treated cells. In comparison with cells treated with Cin alone, $\mathrm{PLC} / \mathrm{PRF} / 5$ cells treated with control $(0.1 \%$ DMSO) or $30 \mu \mathrm{M}$ PFT $\alpha$ only or $30 \mu \mathrm{M}$ PFT $\alpha+1 \mu \mathrm{M}$ Cin caused a decrease in $\mathrm{p} 38$ phosphorylation (Fig. 6b). PFT $\alpha$ markedly inhibited JNK and ERK phosphorylation. Interestingly, Cin-induced phosphorylation of MAPK family proteins were significantly blocked by PFT $\alpha$.

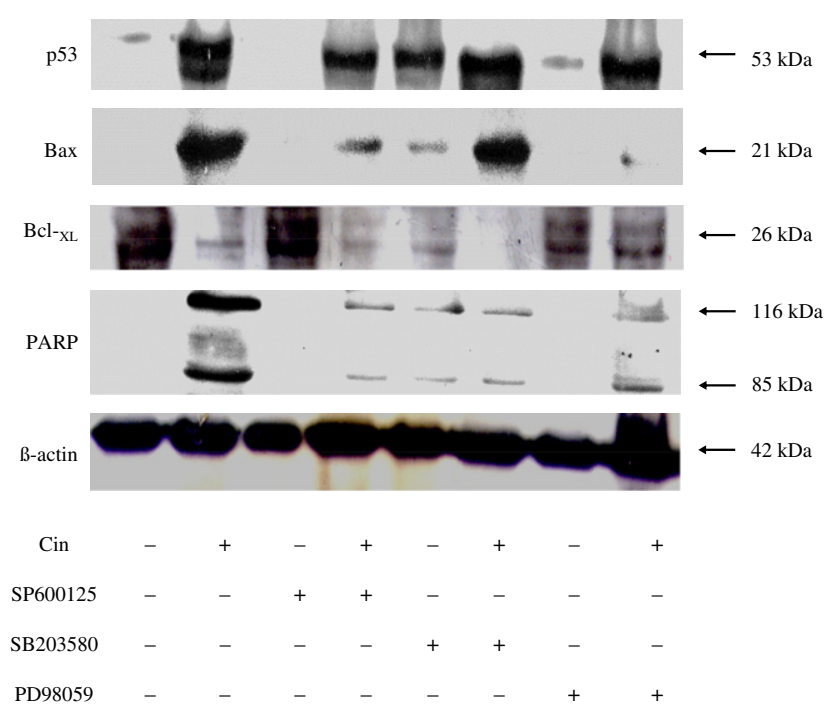

Fig. 5. Effect of MAPK phosphorylation by JNK (SP600125), p38 (SB203580) and ERK (PD98059) inhibitors on Cin-induced apoptosis. $\mathrm{PLC} / \mathrm{PRF} / 5$ cells were treated without or with $20 \mu \mathrm{M}$ JNK inhibitor, $25 \mu \mathrm{M}$ p38 inhibitor and $50 \mu \mathrm{M}$ ERK inhibitor for $1 \mathrm{~h}$, and then in the presence or absence of $1 \mu \mathrm{M}$ Cin for $24 \mathrm{~h}$. Total cell lysates were analyzed by Western blotting analysis with $\mathrm{p} 53, \mathrm{Bax}, \mathrm{Bcl}-\mathrm{xL}$, and PARP antibodies. $\beta$-actin was used as a loading control.

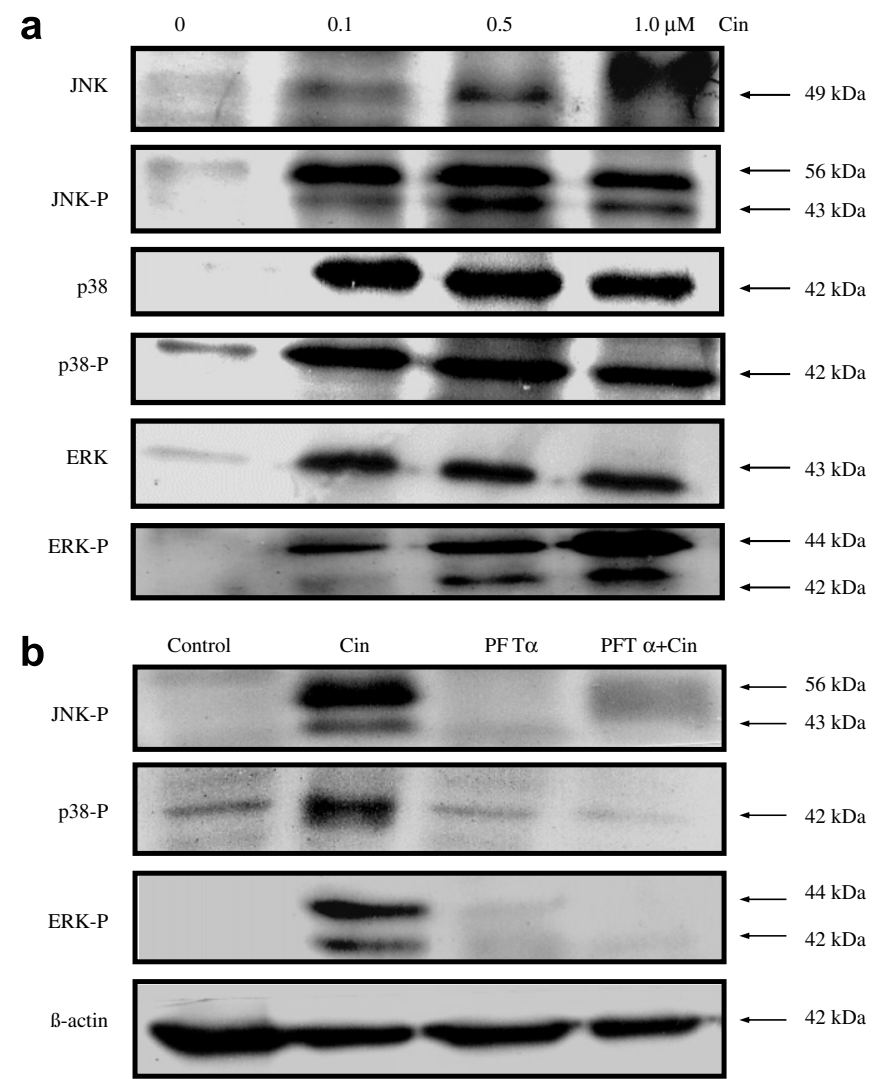

Fig. 6. Induction of Cin on MAPKs activation and effect of PFT $\alpha$ on MAPKs phosphorylation. (a) Total cell lysates of cells untreated (Control; $0.1 \%$ DMSO) or treated with $0.1,0.5$ and $1 \mu \mathrm{M}$ Cin for $24 \mathrm{~h}$. Western blotting was performed with activation of JNK, p38 and ERK antibodies, as well as triggering of their phosphorylated form-specific antibodies. (b) $\mathrm{PLC} / \mathrm{PRF} / 5$ cells were pretreated with or without $30 \mu \mathrm{M}$ PFT $\alpha$ for $1 \mathrm{~h}$, followed by $1 \mu \mathrm{M}$ Cin treatment for $24 \mathrm{~h}$. Total cell lysates were prepared and subjected to immunoblot analysis. $\beta$-actin was used as a loading control.

\section{Discussion}

This study examined the effect of Cin on the MAPK signal transduction and p53 pathways using human hepatoma $\mathrm{PLC} / \mathrm{PRF} / 5$ cells. We found that pretreatment with a p53 inhibitor (PFT $\alpha)$ or specific MAPK inhibitors blocked the process of programmed cell death, and prevented apoptotic signal transduction pathway. Phosphorylation of JNK, p38 and ERK was also inhibited. Cin-induced $\mathrm{PLC} / \mathrm{PRF} / 5$ cell apoptosis was confirmed by two independent methods, the XTT analysis and the Annexin V binding method. Results of these studies indicated that Cin inhibited cell proliferation and induced apoptosis. The apoptotic morphological changes such as cell shrinkage, chromatin condensation, and apoptotic body formation with an intact cell membrane, as well as phosphatidylserine externalization were observed in the Cin-treated cells.

Treatment of PLC/PRF/5 cells with Cin exhibited the up-regulation of p53 and Bax proteins, and the downregulation of $\mathrm{Bcl}_{-\mathrm{xL}}$, as well as causing the PARP to cleave upon the activation of caspase-3. However, the expression 
of CD95 (APO-1/CD95) was not noted. This is consistent with results of previous studies, of which CD95 (APO-1/ CD95) was undetectable in $\mathrm{PLC} / \mathrm{PRF} / 5$ cells treated with chemotherapeutic drugs (Jiang et al., 1999; You et al., 2001). Several studies have shown that the Bcl-2 family of proteins is the central of apoptotic regulation ( $\mathrm{Yu}$ et al., 2003; Choi et al., 2004). Overexpression of Bcl-2 and $\mathrm{Bcl}_{-\mathrm{xL}}$ aborts the apoptotic response while Bax, Bid and Bak activity promotes cell death (Cory and Adams, 2002). Therefore, our results displayed that Cin activated mutant $\mathrm{p} 53$, causing up-expression of Bax, as well as triggering down-expression of $\mathrm{Bcl}_{-\mathrm{xL}}$ to promote apoptotic activity in PLC/PRF/5 cells. Previous study has revealed the role of oxidative stress and the involvement of mitochondria in Cin-mediated apoptosis in leukemia HL-60 cells ( $\mathrm{Ka}$ et al., 2003). We found that after 12-24 h of treatment, Cin-induced cytochrome $c$ release from mitochondria into the cytosol (data no shown) and trigerred the mitochondria apoptotic pathway. p53 has been reported to mediate the up-regulation of Bax (Karpinich et al., 2002), it is possible that Cin-mediated activation of free radicals and toxic metabolites could activate mutant $\mathrm{p} 53$, leading to a p53-dependent, and trigger caspase-3 activation and PARP cleavage. The release of mitochondrial cytochrome $c$ into the cytoplasm was reported to occur with caspase- 3 activation and PARP degradation in the aloe-emodin-induced apoptosis of mutant p53 cells (Pecere et al., 2003).

Recent evidence indicates that the MAPK family protein kinases JNK and p38 are important mediators of apoptosis induced by a variety of stress-related stimuli (Chang and Karin, 2001; Hu et al., 2003). The stress kinases are also activated by chemotherapy drugs, including betulinic acid, cisplatin, epigallocatechin-3gallate and 2-methoxyestradiol (Mansouri et al., 2003; Tan et al., 2003). However, other reports indicated that a different role of ERK and phosphorylated ERK, from pro-apoptotic to pro-survival, which appears to depend on a host of parameters including the cell type, drug dose, and the status of other signal transduction pathways (Fan and Chambers, 2001). In this study, we demonstrated that activation of JNK, p38 and ERK promoted apoptosis by Cin treatment in $\mathrm{PLC} / \mathrm{PRF} / 5$ cells. After Cin treatment, the phosphorylation of JNK, ERK and p38 was pronounced, and appeared to be in a dose-response manner. Natural compounds such as cinnamaldehyde, caffeic acid phenethyl ester and phenethyl isothiocyanate were reported to activate and phosphorylate JNK, p38 and ERK (Hu et al., 2003; Lee et al., 2003; Wu et al., 2005).

PFT $\alpha$ is able to completely inhibit the modulation of Bcl-2 family members, and suppress the PARP cleavage in Cin-treated cells, but not mutant p53. It has been reported that PFT $\alpha$ did not block mutant p53 expression on (C33A) cervical carcinoma cells after staurosporine treatment (Charlot et al., 2006). PFT $\alpha$, a small molecule identified as an inhibitor of p53 transcriptional activity, protects against the toxic side effects of anticancer treatment to the normal tissues; this suggests its potential for use in clinical studies (Komarov and Gudkov, 2000, 2001). It might also interfere with apoptosis of tumor cells that sense DNA damage in response to genotoxic stress (Lorenzo et al., 2002). Our experiments clearly showed that PFT $\alpha$ significantly prevented Cin-mediated apoptosis and blocked the expression of some apoptotic signal factors of PLC/PRF/5 cells.

MAPK inhibitors were shown to modulate the phosphorylation of JNK, p38 and ERK (Wu et al., 2005). Interesting, treatment with JNK (SP600125) and ERK (PD98059) inhibitors significantly attenuated Cin-induced cell death. PLC/PRF/5 cells treated with SP600125 only resulted in the disappearance of mutant $\mathrm{p} 53$, Bax and PARP. Furthermore, co-treatment of JNK inhibitor and Cin exhibited the blocking of Cin-induced Bax and Bcl-xL expression. Cells co-treated with p38 inhibitor (SB203580) and Cin led to elevated levels of mutant p53 and Bax expression, and PARP cleavage. However, cells treated with ERK inhibitor (PD98059) only revealed in the disappearance of PARP cleavage. Thus, co-treatment of cells with PD98059 and $1 \mu \mathrm{M}$ Cin caused a down-regulation of Bax expression. These findings suggest that MAPK inhibitors could modulate Bcl-2 family proteins and suppress PARP degradation.

In this study, we demonstrated that Cin-induced phosphorylation of MAPK family proteins (JNK, p38 and ERK) was completely abolished by PFT $\alpha$ pretreatment. These data suggest that the effects of PFT $\alpha$ on Cin-induced responses may occur by MAPK-dependent signaling mechanisms. Interestingly, treatment with PFT $\alpha$ only or with PFT $\alpha$ and Cin affected the phosphorylation of JNK, p38 and ERK.

In conclusion, Cin treatment inhibited the PLC/PRF/5 cell proliferation. Cin-induced apoptosis was confirmed by the flow cytometry data using Annexin V and XTT assays. The studies described herein are the first to demonstrate the role of MAPK proteins in the Cin-induced apoptotic signaling. Three MAPKs (JNK, p38 and ERK) were activated and phosphorylated in a dose-response manner after Cin treatment in PLC/PRF/5 cells. The PFT $\alpha$ and MAPK inhibitors markedly blocked Cin-induced apoptosis, and suppressed PARP cleavage. The down-regulation of anti-apoptotic ( $\left.\mathrm{Bcl}_{-\mathrm{xL}}\right)$ protein, and up-regulation of Bax protein were modulated by PFT $\alpha$ and MAPK inhibitors (SP600125 and PD98059). Importantly, PFT $\alpha$ attenuated the phosphorylation of JNK, p38 and ERK. Since some parameters affected by Cin are significantly prevented by pretreatment with PFT $\alpha$ and MAPK inhibitors, therefore, modulation of apoptotic pathways through the Bcl2 family proteins, PARP cleavage and the MAPK signaling transduction pathway may become the therapeutic goal for the prevention and treatment of cancer. PFT $\alpha$ may be a useful drug for reducing the side effects of cancer therapy and other types of stress associated with the phosphorylation of MAPKs. 


\section{References}

Adams, J.M., Cory, S., 1998. The Bcl-2 protein family: arbiters of cell survival. Science 281, 1322-1326.

Borner, C., 2003. The Bcl-2 protein family: sensors and checkpoints for life-or-death decisions. Mol. Immunol. 39, 615-647.

Chang, S.T., Chen, P.F., Chang, S.C., 2001. Antibacterial activity of leaf essential oils and their constituents from Cinnamomum osmophloeum. J. Ethnopharmacol. 77, 123-127.

Chang, L., Karin, M., 2001. Mammalian MAP kinase signaling cascades. Nature 410, 37-40.

Charlot, J.F., Nicolier, M., Pretet, J.L., Mougin, C., 2006. Modulation of p53 transcriptional activity by PRIMA-1 and pifithrin- $\alpha$ on staurosporine-induced apoptosis of wild-type and mutated p53 epithelial cells. Apoptosis 11, 813-827.

Choi, S.E., Sohn, S., Cho, J.W., Shin, E.A., Song, P.S., Kang, Y., 2004. 9Hydroxypheophorbide $\alpha$-induced apoptotic death of MCF-7 breast cancer cells is mediated by c-Jun N-terminal kinase activation. J. Photochem. Photobiol. B: Biol. 73, 101-107.

Cory, S., Adams, J.M., 2002. The Bcl-2 family: regulators of the cellular life-or-death switch. Nat. Rev. Cancer 2, 647-656.

Dent, P., Grant, S., 2001. Pharmacologic interruption of the mitogenactivated extracellular-regulated kinase/mitogen-activated protein kinase signal transduction pathway: potential role in promoting cytotoxic drug action. Clin. Cancer Res. 7, 775-783.

Fan, M., Chambers, T.C., 2001. Role of mitogen-activated protein kinases in the response of tumor cells to chemotherapy. Drug Res. Updates 5, 253-267.

Hu, R., Kim, B.R., Chen, C., Hebbar, V., Kong, A.N.T., 2003. The roles of JNK and apoptotic signaling pathways in PEITC-mediated responses in human HT-29 colon adenocarcinoma cells. Carcinogenesis $24,1361-1367$.

Ichijo, H., 1999. From receptors to stress-activated MAP kinases. Oncogene 18, 6087-6093.

Jiang, S., Song, M.J., Shin, E.C., Lee, M.O., Kim, S.J., Park, J.H., 1999. Apoptosis in human hepatoma cell lines by chemotherapeutic drugs via Fas-dependent and Fas-independent pathways. Hepatology 29, 101-110.

Ka, H., Park, H.J., Jung, H.J., Choi, J.W., Cho, K.S., Ha, J., Lee, K.T., 2003. Cinnamaldehyde induces apoptosis by ROS-mediated mitochondrial permeability transition in human promyelocytic leukemia HL-60 cells. Cancer Lett. 196, 143-152.

Karpinich, N.O., Tafani, M., Rothman, R.J., Russo, M.A., Farber, J.L., 2002. The course of etoposide-induced apoptosis from damage to DNA and 553 activation to mitochondrial release of cytochrome $c$. J. Biol. Chem. 277, 16547-16552.

Koch, S., Frevtag, von Loringhoven.A., Kahmann, R., Hofschneider, P.H., Koshy, R., 1984. The genetic organization of integrated hepatitis B viral DNA in the human hepatoma cell line PLC/PRF/5. Nucl. Acid Res. 12, 6871-6886.

Koh, W.S., Yoon, S.Y., Kwon, B.M., Jeong, T.C., Nam, K.S., Han, M.Y., 1998. Cinnamaldehyde inhibits lymphocyte proliferation and modulates T-cell differentiation. Int. J. Immunopharmacol. 20, 643660.

Komarov, E.A., Gudkov, A.V., 2000. Suppression of p53: a new approach to overcome side effects of antitumor therapy. Biochemistry 65, 41-48.

Komarov, E.A., Gudkov, A.V., 2001. Chemoprotection from p53dependent apoptosis: potential clinical application of the p53 inhibitors. Biochem. Pharmacol. 62, 657-667.

Komarov, P.G., Komarova, E.A., Kondratov, R.V., Tselkov, K.C., Coon, J.S., Chernov, M.V., Gudkov, A.V., 1999. A chemical inhibitor of p53 that protects mice from the side effects of cancer therapy. Science 285, 1733-1737.
Kroemer, G., Reed, J.C., 2000. Mitochondrial control of cell death. Nat. Med. 6, 513-519.

Lee, Y.J., Kuo, H.C., Chu, C.Y., Wang, C.J., Lin, W.C., Tseng, T.H., 2003. Involvement of tumor suppressor protein $\mathrm{p} 53$ and p 38 MAPK in caffeic acid phenethyl ester-induced apoptosis of C6 glioma cells. Biochem. Pharmacol. 66, 2281-2289.

Lorenzo, E., Ruiz, C.R., Quesada, A.J., Hernandez, G., Rodriguez, A., Rivas, A.L., Redondo, M., 2002. Doxorubicin induces apoptosis and CD95 gene expression in human primary endothelial cells through a p53-dependent mechanism. J. Biol. Chem. 277, 10883-10892.

Mansouri, A., Ridgway, L.D., Korapati, A.L., Zhang, Q., Tian, L., Wang, Y., Siddik, Z.H., Mills, G.B., Claret, F.X., 2003. Sustained activation of JNK/p38 MAPK pathways in response to cisplatin leads to Fas ligand induction and cell death in ovarian carcinoma cells. J. Biol. Chem. 278, 19245-19256.

Meier, P., Finch, A., Evan, G., 2000. Apoptosis in development. Nature 407, 796-801.

Mitry, R.R., Sarraf, C.E., Havlik, R., Habib, N.A., 2000. Detection of adenovirus and initiation of apoptosis in hepatocellular carcinoma cells after Ad-p53 treatment. Hepatology 31, 885-889.

Muller, M., Wilder, S., Bannasch, D., Israeli, D., Lehlbach, K., Li-Weber, M., Friedman, S.L., Galle, P.R., Stremmel, W., Oren, M., Krammer, P.H., 1998. p53 activates the CD95 (APO-1/Fas) gene in response to DNA damage by anticancer drugs. J. Exp. Med. 188, 2033-2045.

Pecere, T., Sarinella, F., Salata, C., Gatto, B., Bet, A., Vecchia, F.D., Diaspro, A., Carli, M., Palumbo, M., Palu, G., 2003. Involvement of p53 in specific anti-neuroectodermal tumor activity of aloe-emodin. Int. J. Cancer 106, 836-847.

Perry, L.M., 1980. Medicinal Plants of East and Southeast Asia Attributed Properties. The MIT Press, Massachusetts, pp. 197-198.

Shaughnessy, D.T., Setzer, R.W., DeMarini, D.M., 2001. The antimutagenic effect of vanillin and cinnamaldehyde on spontaneous mutation in salmonella TA104 is due to a reduction in mutations at GC but not AT sites. Mutat. Res., 55-69.

Tan, Y.M., Yu, R., Pezzuto, J.M., 2003. Betulinic acid-induced programmed cell death in human melanoma cells involves mitogenactivated protein kinase activation. Clin. Cancer Res. 9, 2866-2875.

Thompson, C.B., 1995. Apoptosis in the pathogenesis and treatment of disease. Science 267, 1456-1462.

Usta, J., Kreydiyyeh, S., Bajakian, K., Nakkash-Chmaisse, H., 2002. In vitro effect of eugenol and cinnamaldehyde on membrane potential and respiratory chain complexes in isolated rat liver mitochondria. Food Chem. Toxicol. 40, 935-940.

Wolf, B.B., Green, D.R., 1999. Suicidal tendencies: apoptotic cell death by caspase family proteinases. J. Biol. Chem. 274, 20049-20052.

Wu, S.J., Ng, L.T., Lin, C.C., 2005. Cinnamaldehyde-induced apoptosis in human PLC/PRF/5 cells through activation of proapoptotic Bcl-2 family proteins and MAPK pathway. Life Sci. 77, 938-951.

Xia, Z., Dickens, M., Raingeaud, J., Davis, R., Greenberg, M., 1995. Opposing effects of ERK and JNK-p38 MAP kinases on apoptosis. Science 270, 1326-1331.

You, K.R., Shin, M.N., Park, R.K., Lee, S.O., Kim, D.G., 2001. Activation of caspase-8 during N-(4-hydroxyphenyl) retinamideinduced apoptosis in Fas-defective hepatoma cells. Hepatology 34, 1119-1127.

Yu, W., Sanders, B.G., Kline, K., 2003. RRR- $\alpha$-tocopheryl succinateinduced apoptosis of human breast cancer cells involves Bax translocation to mitochondria. Cancer Res. 63, 2483-2491.

Zhang, C.L., Wu, L.J., Tashiro, S.I., Onodera, S., Ikejima, T., 2004. Oridonin induces a caspase-independent but mitochondria- and MAPK dependent cell death in the murine fibrosarcoma cell line L929. Biol. Pharm. Bull. 27, 1527-1531. 